\title{
Effect of Corrugation Geometry and Shape on Energy Absorption of Composite Plate.
}

\author{
Khalid A. Elbkory ${ }^{1}$, Fathi A.al ssahly ${ }^{2}$ \\ ${ }^{1}$ Department of Mechanical and Industrial Engineering, College of Engineering, Elmergib \\ University, Libya \\ ${ }^{2}$ Department of Marine Mechanical, College of Marine Resources Alasmarya Islamic University, \\ Libya \\ DOI: https://doi.org/10.21467/proceedings.4.7 \\ * Corresponding author email: khalidattia1981@gmail.com
}

\begin{abstract}
It has been observed that there is a considerable interest in recent years regarding materials which have high crushing ability particularly in energy absorption in relation to car and allied industries. An important aspect of the crushing ability of materials is its specific energy absorption value which is much greater for polymer composite than conventional metallic material. In this research, series experiments were conducted including testing of the capabilities of composite material as an energy absorber with comparison to metallic materials. The method used in the current research is to fabricate and test a series of composite plate specimens with different corrugation profile, these are: sinusoidal, triangle and square. All these specimens were fabricated from glass fibers with hand layup technique. Each profile has three different types of specimens: single plate, double plates and triple plates. The corrugated plates are fixed over each other and subjected to the same kind of compression load. All these models have been exposed to lateral crushing load and then the collapse of these models have been observed and the results have been recorded. Finally; all the results obtained in this research were recorded and discussed. It is found that the highest value of specific energy absorption was $(2.472 \mathrm{Kj} / \mathrm{Kg})$ recorded for level three square profile specimen. However, the lowest value $(0.878 \mathrm{Kj} / \mathrm{Kg})$ was recorded for level two triangle profile specimen.

Keywords: Knitted Fabrics, Energy Absorption, Crashworthiness, Axial Crushing
\end{abstract}

\section{Introduction}

The performance of composite materials that have incurred damage has long been a topic of great interest and study. Today the use of composite materials in different kinds of applications is accelerating rapidly. Composite materials have become common engineering materials and are designed and manufactured for various application including automotive components, sporting goods, aerospace parts, consumer, and in the marine and oil industries [1].

The crashworthiness performance of automobile components to perform remarkably under crash conditions is very important to vehicle occupants. As stated by Reid [2] design of crashworthy structure requires both knowledge of structural geometry and understanding of the properties and deformation mechanism of the materials and components used. Work on

(C) 2018 Copyright held by the author(s). Published by AIJR Publisher in Proceedings of First Conference for Engineering Sciences and Technology (CEST-2018), September 25-27, 2018, vol. 2.

This is an open access article under Creative Commons Attribution-NonCommercial 4.0 International (CC BY-NC 4.0)

AiR license, which permits any non-commercial use, distribution, adaptation, and reproduction in any medium, as long as the original work is properly cited. ISBN: 978-81-936820-6-7 
crushing behaviour of metal shell has advanced and well understood. Research groups have, since 1960s, carried out research, toward crashworthiness of metallic devices using empty thinwalled tube with different cross-sections[3-5]. The previous works on the axial crushing of fiber reinforced plastic composite tubes has indicated that significant specific energy absorption can be obtained from these materials, under some circumstances exceeding the ones that can be obtained from metal tubes [6-7].

In recent years there is an increasing demand in the use of composite materials for the automotive and aerospace industry. Composite material and in particular their anisotropy offers vast potential for optimally tailoring a design to meet crashworthiness performance requirements. Therefore, intensive research has been carried out to examine the failure mechanism of no hybrid and hybrid composite structure [8-13]. Looking back implementation of composite materials in the field of crashworthiness is attributed to Hull, who in 1980s and 1990s has studied extensively the crushing behaviour of fiber reinforced composite material. He found that the composite materials absorb high energy in the face of the fracture surface energy mechanism rather than plastic deformation as observed for metals[14,15]. Composite materials are playing a key role in the development of lightweight integral armor for military vehicles such as tanks or armoured personnel carriers. For future applications, revolutionary approaches are required to significantly reduce (up to 50\%) the mass of these systems and improve their mobility and trans- portability without sacrificing survivability or maintrainability[16].

This paper experimentally investigating the effect of Corrugation geometry and shape on energy absorption of composite plates. Three different corrugation profile are tested which are sinusoidal, triangle and square. subjected to quasi-static compression load. All kind has three types of specimens referred to as level one, level two and level three. These tested models have been fabricated and tested under the same conditions.

\section{2-Profiles Manufacturing}

The corrugated profile are manufactured using metallic dies, Specifically iron. Hand lay-up process was used to fabricate all composite specimens. The material used for fabricating composite specimens are woven roving glass fiber and epoxy. The specification of the material used are given in table (1) the specimens were fabricated by placing the woven roving fiber glass in fabrication model as layers on each other. The woven roving fiber is passed through a resin bath, causing resin impregnation. The fabricated specimens were cured at room temperature for 24 hours to provide good hardness and shrinkage. Then the cured specimens were extracted from fabrication model to prepare them for the crushing test. Figure(1)-a shows 
Effect of Corrugation Geometry and Shape on Energy Absorption of Composite Plate

the three metallic dies used for the fabrication of corrugated composite specimens using hand layup process and Some of tested specimens are show in figure(1) b, c, and d.

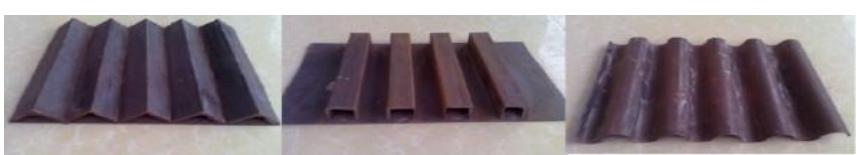

(a)

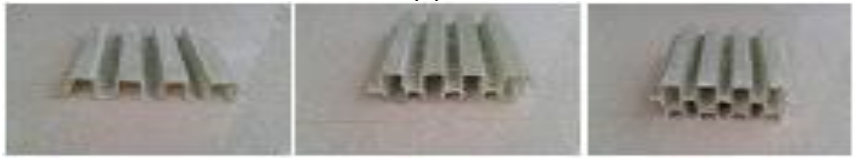

(b)
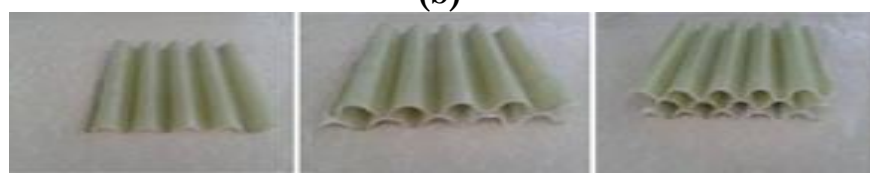

(c)
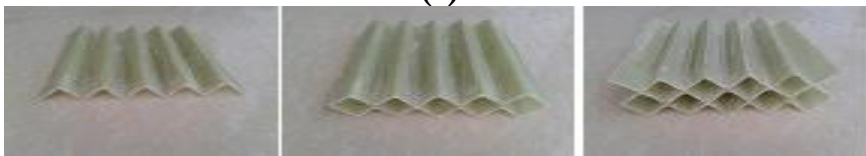

(d)

Figure 1.(a) different metallic dies used for specimens fabrication (b) square specimens (c) sinusoidal specimens and (d) triangular specimens

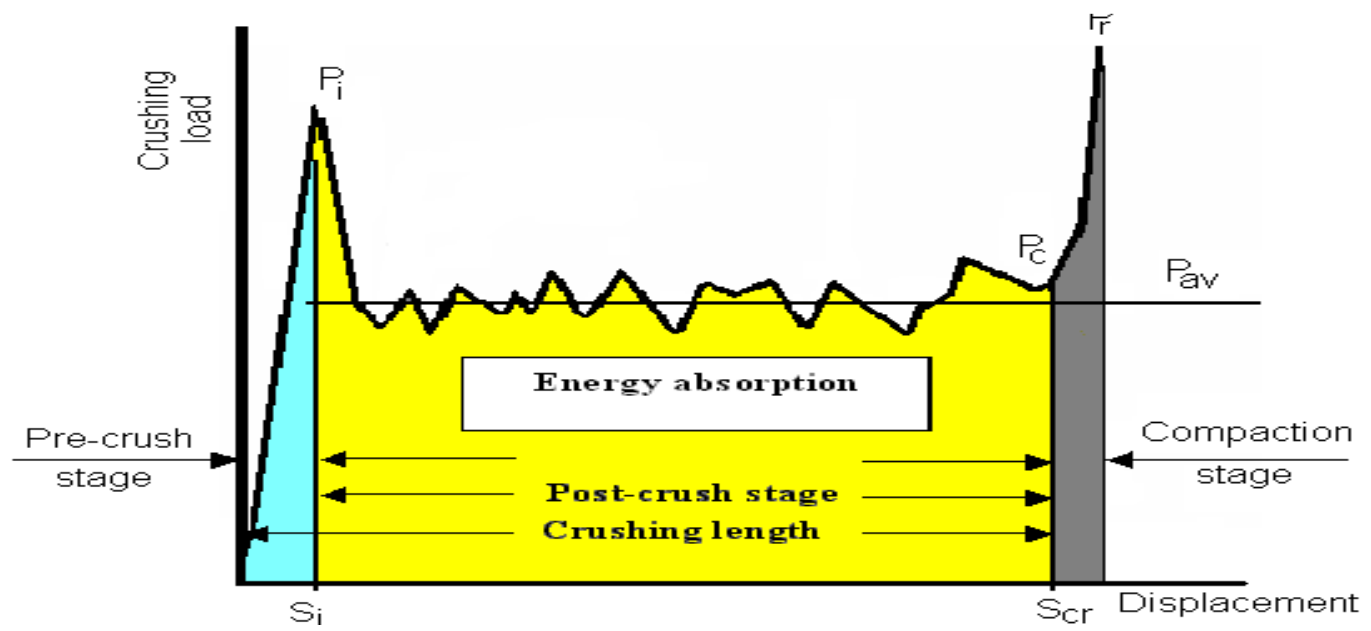

Figure 2: Schematic representation of a typical load-displacement curve of a corrugated composite with its main parameters

Table 1: Types of used constituents

\begin{tabular}{|l|l|l|}
\hline 2.1.1 Epoxy resin & $\begin{array}{l}\text { UK Epoxy Resins UKH 137 } \\
\text { Epoxy }\end{array}$ \\
\hline Hardener & $\begin{array}{l}\text { UK Epoxy Resins UKH 136 } \\
\text { Hardener }\end{array}$ \\
\hline Woven roving E-glass fiber & Synthetic fiber: $500 \mathrm{~g} / \mathrm{m}^{2}$ \\
\hline No. of layers of each specimens & Four layers \\
\hline
\end{tabular}




\section{3-Test Procedure}

The specimens were tested in quasi-static axial compression between two flat plates. ASTMD1621 standards, with full-scale load range of $4000 \mathrm{kN}$ was used. Three replicate tests were conducted for each type of models. All models were compressed at a rate of $2.5 \mathrm{~mm} / \mathrm{min}$ until limited crush, which implies complete compaction of tested specimen and load records increases sharply is reached. Load and displacement were recorded by automatic data acquisition system.

\section{4-Results and Discussion}

The tested specimens collapsed following the failure mode described by Hull[15]. As illustrated in figure (2). The load-displacement curve can be divided into three distinct regions. In region I the load $\mathrm{P}$ increases rapidly and reaches a maximum $\mathrm{P}_{\max }$ before dropping. In region II the load oscillates about an average $\mathrm{P}^{-}$and a series of folds form successively in the corrugated plate so that a folded zone grows progressively. For the last stage (region III), the load increases rapidly representing the end of the test. The detailed discussion of the results are presented in the proceeding section, that involves crush stages and load displacement curve of composite specimens.

In this study, 27 specimens were made and tested under the same conditions. These types of specimens are divided to three levels. Level one has single corrugated plate, level two has two plates, and level three has three corrugated plates. Each level has three different profiles: Sinusoidal, triangular, and square profiles. The specimens that recorded the highest value and the lowest value of the specific energy absorption will be explained.

\section{1-Three corrugated composite plate with square profile:}

Typical load displacement curve for square under quasi-static compression load are shown in figure (3a). As it can be seen curve, the load increases gradually with the increase in the displacement up to initial failure where maximum load achieved $41 \mathrm{KN}$ at a displacement of $20 \mathrm{~mm}$. Subsequently load drops down to $22 \mathrm{KN}$ at a displacement of $25 \mathrm{~mm}$. As compression load increases, it was observed that lateral split was formed (see figure 3b ), and propagate causing fall down of load displacement curve. This case of crushing progress continues until the end of the test, where the specimen was completely crushed.

\section{2-Two corrugated composite plate with triangular profile:}

In general two triangular specimen crushed in the same manner as composed specimen except that no fracture occurred for two triangular specimen. As shown in Figure (4a), the crushing load increases until the compression is about $14 \mathrm{~mm}$ when full resistance is developed with $52 \mathrm{KN}$ load. Immediately after this stage start (plastic deformation) the load slow down until the compression is about $21 \mathrm{~mm}$ when full resistance is developed with $16 \mathrm{KN}$, after that increase resistance

the loading until compression $58 \mathrm{KN}$ at $25 \mathrm{~mm}$ after that droop slow until the compression $20 \mathrm{KN}$. Consequently load increases during this crushing stage followed by slight fluctuation the dramatic increase at the end of crushing test (see figure (4b). 


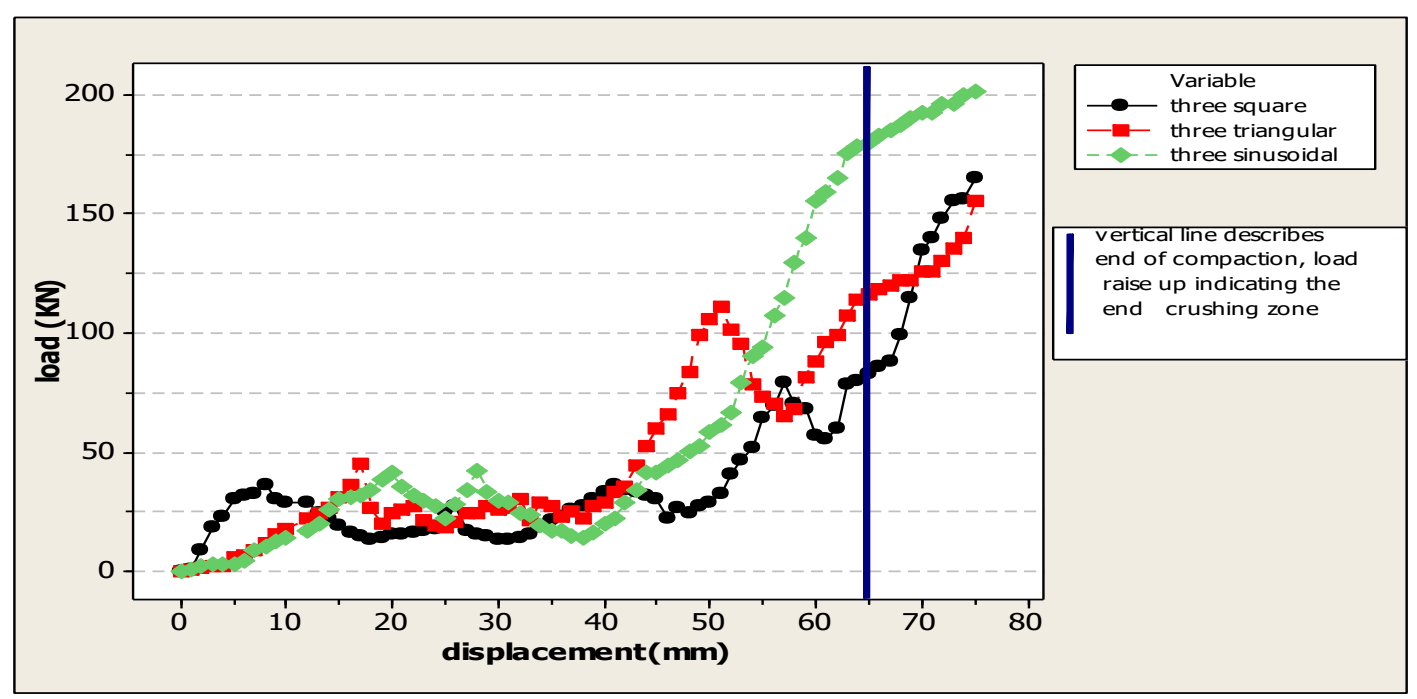

(a)
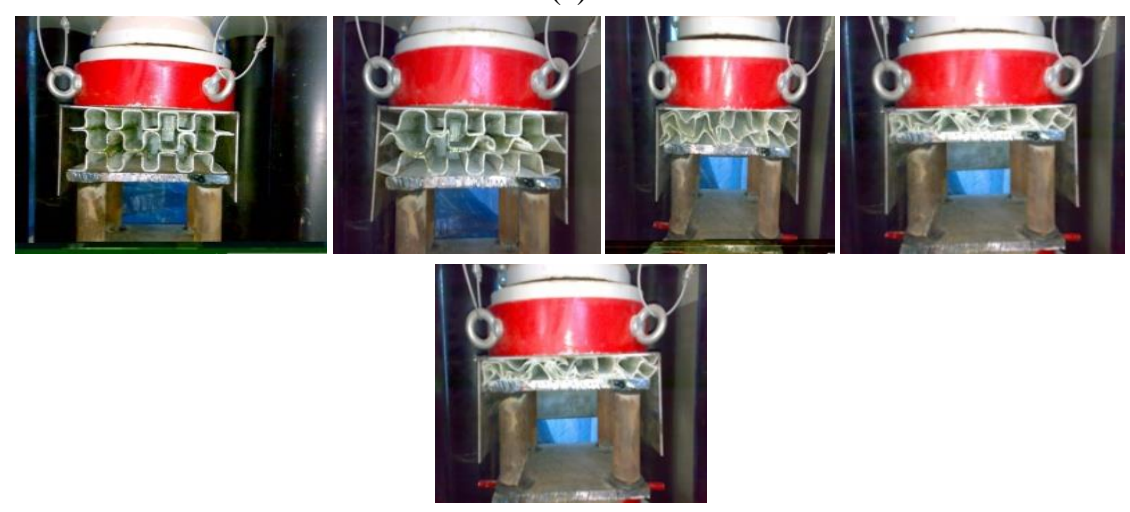

(b)

Figure 3. (a) load-displacement curve of level three of composite specimens, (b) deformation history of three level plate with square profile 
Elbkory et al., CEST-2018, AIJR Proceedings 4, pp.403-410, 2018

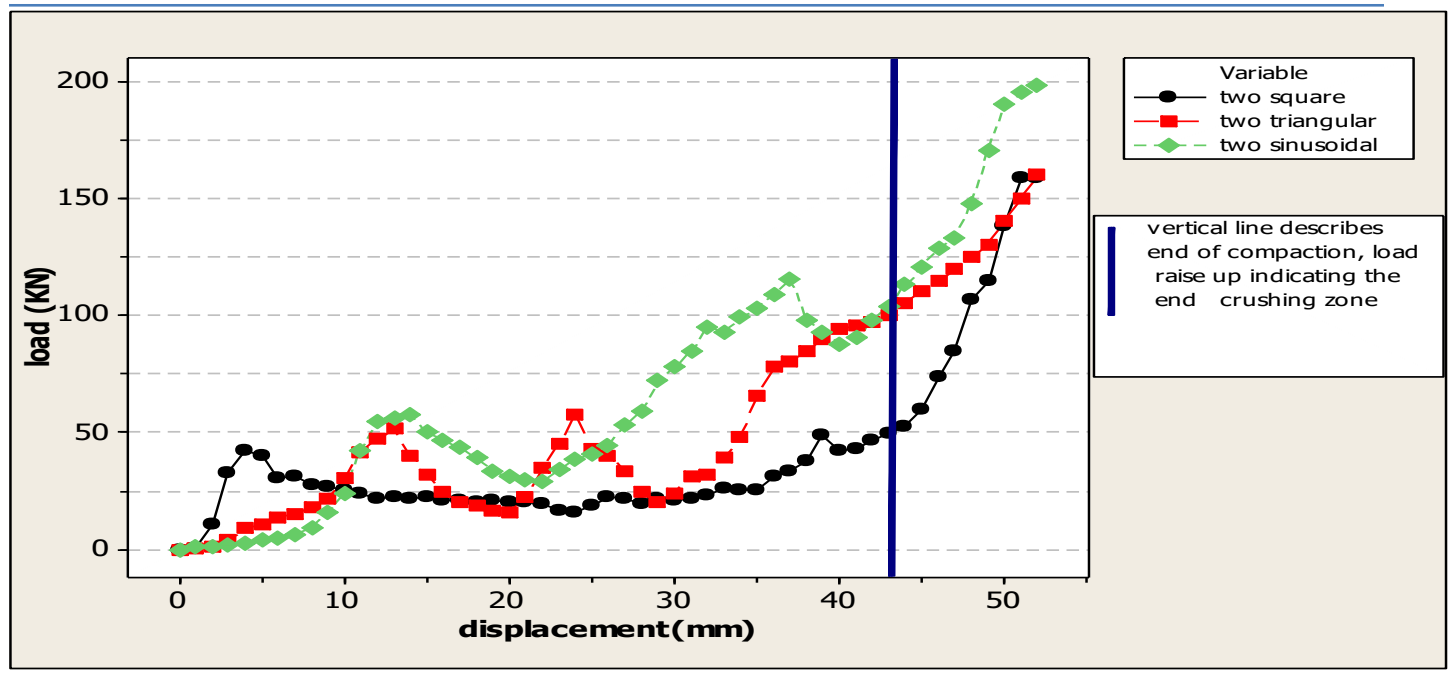

(a)
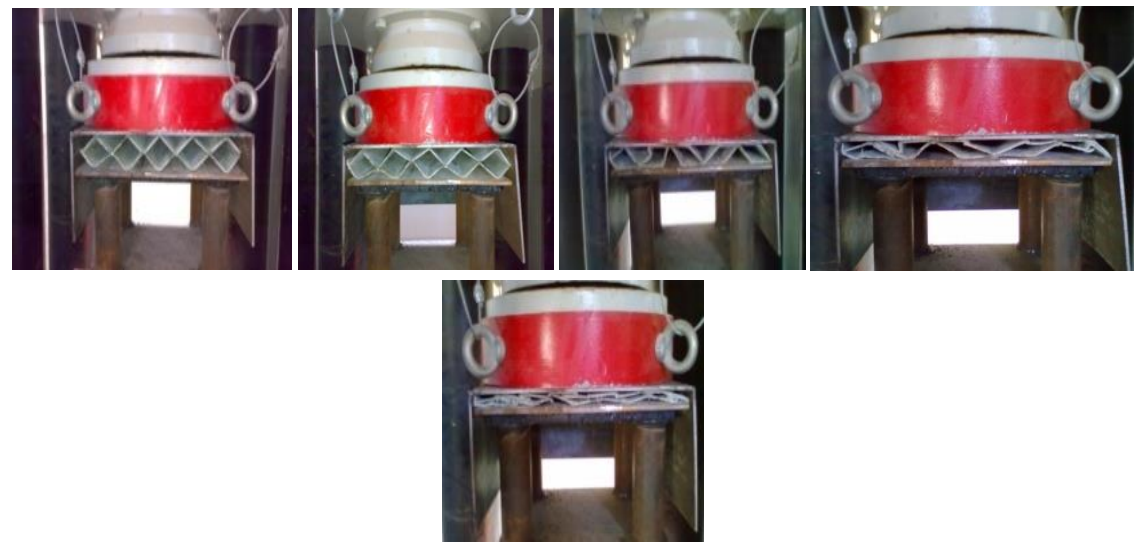

(b)

Figure 4. (a) load-displacement curve of level two of composite specimens, (b) deformation history of two level plate with triangular profile

\section{Crushin Energy Absorption}

The energy absorption capability can be estimated by knowing different parameter. These parameters are illustrated in the following section.

5.1 Total Energy Absorption (E): The total energy absorbed or the total work done, Wt, in crushing of composite specimens is the area under the load-displacement curve. It can be obtained by numerical integration of the load displacement curve.

$\mathrm{Wt}=\int_{S i}^{S c r} P_{a v} d S=P_{a v}\left(S_{c r}-S_{i}\right)$

where, as they are indicated in figure 3, Si and Scr are the initial and final useful crush stroke and $P_{a v}$ is the mean crush load which obtained by averaging the applied loads during post 
Effect of Corrugation Geometry and Shape on Energy Absorption of Composite Plate

crush stage. The load-deformation characteristic is a measure of the energy absorption capacity. It differs from one structure to another, and it depends on the mechanism of deformation involved and the material used.

5.2 Specific Energy Absorption (Esp): To compare different materials or different geometry of specimens, it is necessary to consider the specific energy. The specific energy is defined as the amount of energy absorbed per unit mass crushed material $(\mathrm{m})$. Therefore, the specific energy (Esp) that is dependent on the structure material was used for comparing the energy absorption of all specimen kinds. Specific energy absorption (Esp) can be calculated as;

Esp $=\frac{W_{t}}{m}$

After all the lateral cracking tests are completed, the results obtained from these tests can be seen in Table 2, and represented by the curve in Figure (5). Looking carefully to the results obtained with a specific absorption from the third-level samples, the square sample still has the highest values of initial failure load of $(2,472 \mathrm{kj} / \mathrm{kg})$. From the table, it can be seen that the triangular samples recorded the lowest value of $(0.878 \mathrm{kj} / \mathrm{kg})$.

Table 2: Crashworthiness parameters of lateral tests for all specimens

\begin{tabular}{|c|c|c|c|c|c|c|c|c|}
\hline The level & Sp-type & ${ }_{(\mathrm{KN})} \boldsymbol{P}_{\max }$ & $(\mathbf{K N}) \bar{P}$ & $(\mathbf{K} \mathbf{j}) E_{t}$ & $\begin{array}{c}\text { W } \\
(\mathrm{Kg})\end{array}$ & $(\mathrm{KJ} / \mathrm{KN}) \boldsymbol{E}_{\boldsymbol{S P}}$ & $\begin{array}{c}\text { CFE* }^{*} \\
\%\end{array}$ & $\begin{array}{c}\text { SE** } \\
\%\end{array}$ \\
\hline \multirow{3}{*}{ One level } & sinusoidal & 113 & 65.66 & 0.525 & 0.470 & 1.117 & 58.1 & 90 \\
\hline & triangular & 89 & 51.79 & 0.725 & 0.400 & 1.812 & 58.19 & 80 \\
\hline & square & 68 & 40.62 & 0.649 & 0.370 & 1.754 & 58.69 & 66 \\
\hline \multirow{3}{*}{ Two level } & sinusoidal & 115.6 & 59.62 & 1.304 & 0.940 & 1.387 & 90 & 73 \\
\hline & triangular & 58 & 31.95 & 0.703 & 0.800 & 0.878 & 61 & 60 \\
\hline & square & 49 & 36.23 & 1.304 & 0.740 & 1.762 & 91 & 73 \\
\hline \multirow{3}{*}{ Three level } & sinusoidal & 48 & 44.67 & 1.608 & 1.410 & 1.140 & 86 & 62 \\
\hline & triangular & 111 & 42.49 & 1.827 & 1.200 & 1.522 & 87 & 66 \\
\hline & square & 79 & 44.26 & 2.744 & 1.110 & 2.472 & 95 & 75 \\
\hline
\end{tabular}

(CFE*) Crush Force Efficiency ( $E^{* * *)}$ Stroke Efficiency

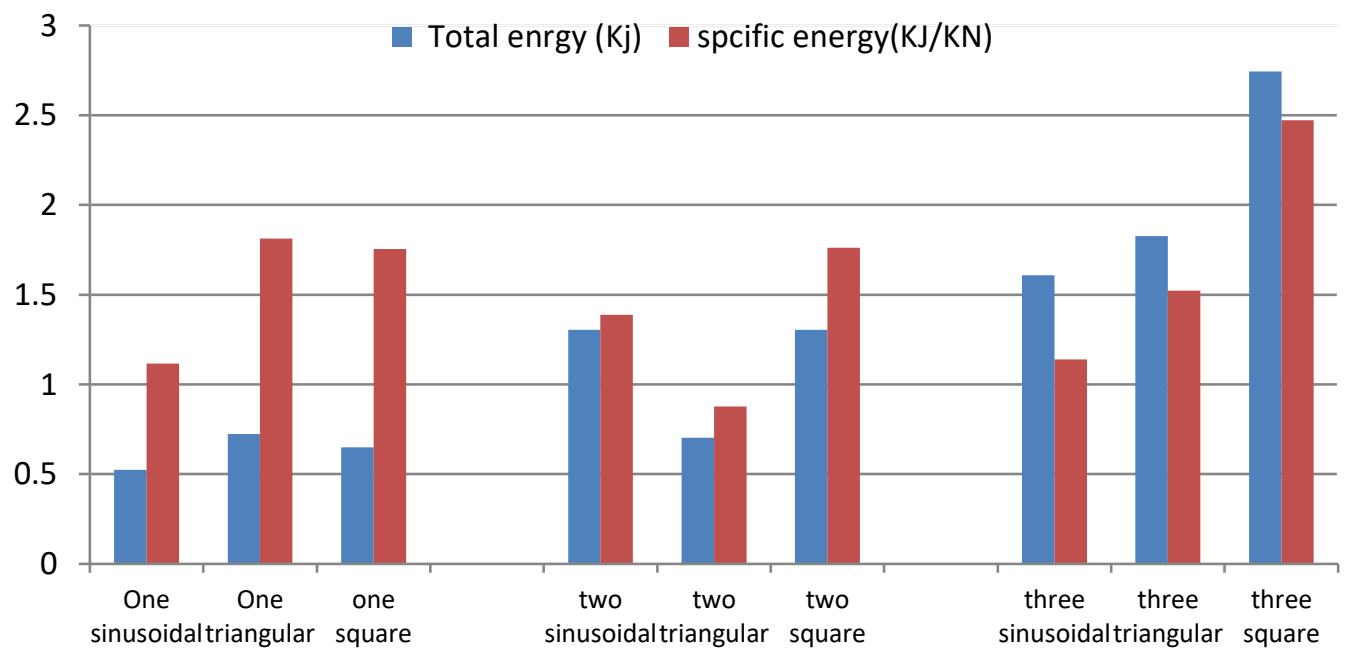

Figure 5. Total energy and specific energy of all specimens 


\section{6-Conclusion}

A series of composite plates with different corrugation profile (sinusoidal, square, and triangular) has been subjected to quasi-static compression load. The difference of the specimens' shape offer a compare between them in terms of the effect of the corrugation profile in energy absorption capability. Based on the results obtained, it can be noted that, the specimen geometry has a considerable affect on energy absorption capability and load carrying capacity; it has been observed that the change in corrugation profile has important affect on energy absorption capability, where the specimens of square profile recorded the highest values of energy absorption capability comparing to specimens with sinusoidal and triangular profile; the specific energy absorption and load carrying capacity increased with the increase of the number of corrugated plates and the relationship between the two factors is directly proportional; the highest value of specific energy absorption of group A specimens has been recorded by the level three square specimens to be $(2.472 \mathrm{KJ} / \mathrm{Kg})$. However, triangular specimens come second with $(1.812 \mathrm{KJ} / \mathrm{Kg})$, and specimens of two triangular recorded the lowest value of $(0.878 \mathrm{KJ} / \mathrm{Kg})$.

\section{Reference.}

[1] Elfetori F. Abdewi, S. Suliman, A.M.S. Hamouda, E.Mahdi. (2006), Effect of Geometry on the Crushing Behaviour of laminated corrugated Composite Tubes.journal of Materials Processing Technology 172 394399.

[2] Reid SR. Plastic deformation mechanism in axially compressed metal tubes used as impact energy absorbers. Int J Mech Sci 1993;35:1035-52.

[3] Reddy TY, Al-Hassani STS. Axial crushing of wood filled square metal tubes. Int J Mech Sci 1993;35:23146.

[4] Wu L, Carney JF. Experimental analysis of collapse behaviour of braced elliptical tubes under lateral compression. Int J Mech Sci1998;40(8):761-77

[5] Beardmore P, Johnson CF. Compos Sci Technol 1986;26:251-81.

[6] Hamada H, Coppola JC, Hull D, Maekawa Z, Sato H.Composites 1992;23:245-52.

[7] Mamalis AG, Manolakos DE, Viegelahn GL. J ComposMater1990;25:72-90.

[8] Farely GL. Energy absorption of composite materials. J Compos Mater 1986;20:322-34.

[9] Mamalis GD, Manolakos E, Demosthenous GA, Ioannidis MB. Analytical modelling of the static and dynamic axial collapse of thin-walled fibreglass composite conical shells. Int J Impact Eng1997;19(56):477-92.

[10] Ramakrishna S, Hamada H. Energy absorption characteristics o crash worthy structural composite materials. Key Eng Mater1998;(141-143):585-620.

[11] Mahdi E, Sahari BB, Hamouda AMS, Khalid YA. An experimental investigation into crushing behaviour of filament wound laminated cone-cone intersection composite shell. Compos Struct2001;51(3):211-9

[12] Mahdi E, Sahari BB, Hamouda AMS, Khalid YA. Crushing behaviour of cone-cylinder-cone composite system. Mech Compos Mater Struct 2002;9(2):99-117

[13] Drzal LT. Composite property dependence on thefiber, matrix and interphase. In: Tough composite materials, Noyes; Park Ridge, 1985. p. 207 222 .

[14] Hull D. Energy absorption of composite materials under crash conditions. In: Progress in Science and Engineering of Composites, Proceedings of the 4th International Conference on Composite Materials (ICCM/4), Tokyo, 25-28 October 1982. p. 861-70.

[15] Hull D. A unified approach to progressive crushing of fibre reinforced composite tubes. Compos Sci Technol 1993;35(3/4):231-46.

[16] Williams JG, James MR, Morris WL. Formation of the inter- phase in organic-matrix composites. Composites 1994;25:757士62. 